\title{
Estimation of Stature from Foot Dimensions from Female Population of Rajasthan
}

\author{
Faray Jamal $^{1,2}$, Rishu Agarwal ${ }^{2}$, Aditi Mishra ${ }^{2,3}$, Ulhas Gondhali ${ }^{4}$ \\ ${ }^{1}$ Assistant Professor, Lovely Professional University, Phagwara, 14441, India, ${ }^{2}$ M.Sc, Mody University of Science \\ and Technology, Rajasthan-332311, India, ${ }^{3}$ Research Scholar, RashtriyaRakshaUniversity, Gujarat, India, \\ ${ }^{4}$ Lecturer, O. P Jindal Global University, 131001, India
}

\begin{abstract}
Background: Analyzing and identifying evidences found at crime scene plays a crucial role in apprehending the offenders and putting them behind bars. Stature Estimation has a significant importance when it comes to narrowing down the list of suspects. At various instances footprints are left behind at the crime scenes as vital evidence and can be utilised for generating the stature of the individual/s connected with the crime scene.

Method: The present study focuses on female population belonging to Rajasthan. Major objective is to determine relation between foot dimensions and stature $(n=111)$. Foot dimensions, mainly foot length and breadth were calculated using standard measurements method. The samples were statistically analyzed; regression equations were generated for length and width of left and right foot.

Conclusion: The predicted R-squared values showed quite significant value of left foot being (0.09) and right foot being (0.04). SEE was calibrated through the regression equations. Width of both the left and right foot were found to be more significant measurements for estimating stature in Rajasthan Population.
\end{abstract}

Keywords: Forensic science, Anthropometry, Foot length and breadth, Stature estimation, Regression analysis.

\section{Introduction}

The application of Anthropology in the field of forensic science is to yield answers to questions that arise due to legal and public concerns. Numerous cases have been reported in the past where, skeletal remains were recovered and identification had to be made. Forensic Anthropometry which was initiated by Alphonse Bertillon back in 1800s was used to record the data of the individuals who were suspects or criminals by taking various body measurements. ${ }^{1}$ It still plays an extremely vital role in identifying and reconstructing such events where the death is in question.It becomes even more

\section{Corresponding Author:}

\section{Ulhas Gondhali}

O.P. Jindal Global University, Sonipat-131001, India

e-mail: gondhali.ulhas@gmail.com necessary when we encounter natural calamities such as earthquake, tsunami or a disaster like bomb blasts, air plane crash, where numbers of deceased are uncertain. Countless researches have been utilized in deciphering the gender, ethnicity, age at the time of death and the physical make up or the stature from the recovered fragmented cadaver.

Stature Estimation has been conducted by numerous scholars over the time, the records dates back to $1899 ; \mathrm{K}$. Pearson suggested various parameters and equations for evaluating the height and the correlation found among bones and stature. In his memoir it has been mentioned that one equation or a parameter cannot be used to decipher stature of every population that have a different ethnic and ancestral background. ${ }^{2}$

Estimating stature through bones has been accomplished but few studies focus on determining the same using foot dimensions. Being a crucial part of 
anthropology they play a decisive role in crime scene investigations. The possibility of their occurrence at a crime scene is uncanny. They can be found in numerous forms, latent, patent as well as plastic impressions. Once located if they are carefully lifted or recorded with correct measurements they can be used to determine the height of the person that was involved at the crime scene. Each print holds great evidentiary value and thus can be aided in narrowing down the investigation. Determining the stature with foot, hand length and breadth was conducted in Turkey on volunteers and the equation derived using foot dimensions yielded more accurate results. ${ }^{3}$ Similar studies have been reported in the subcontinent of India, the selected population group being small and restricted to states. Height was estimated using foot measurements in Gujrat Region, Kori Population of Kanpur (U.P) were analyzed on similar body measurement parameters such as full arm length, foot length and breadth, knee length, the accurate measurements were yielded by the foot dimensions. ${ }^{4,5}$ Study conducted on tribal males of Udaipur district of Rajasthan yielded high core relation between the left and right foot length and the stature of the individuals under study. ${ }^{6}$ In the present study, the focus is drawn towards stature estimation and determination through human foot of the young females hailing from Rajasthan.

\section{Materials and Methodology}

Sample collection was conducted at Mody University of Science and Technology, Laxmangarh, Rajasthan. Females who originally hail from the state of Rajasthan were the key targets. A total of 111 samples were collected with the age between 17-23 years, height was calculated using standard measurement criteria; the measuring scale was drawn on a straight wall. The foot prints were taken on plane A4 size sheets. Consent was taken from each individual for maintaining the anonymity and that the data is being collected for the sole purpose of research. Stature was calculated by asking the individual to take off shoes and socks and was made told to stand straight in front of the measuring scale; using a ruler the accurate distance was measured. The foot impressions were drawn with the help of the pen aligning the edge of the skin on an A4 sheet with the support of the flat tile surface. Both the foot were drawn on two different sheets. The length was the foot was taken from the heel to the apex of the toe represented as LFL for Left Foot Length and RFL for Right Foot
Length. The breadth was measured from either side of the metatarsals represented as LFW for Left Foot Width and RFW for Right Foot Width. These measurements were brought about on the drawn images of the foot on the piece of paper. (Figure 1)

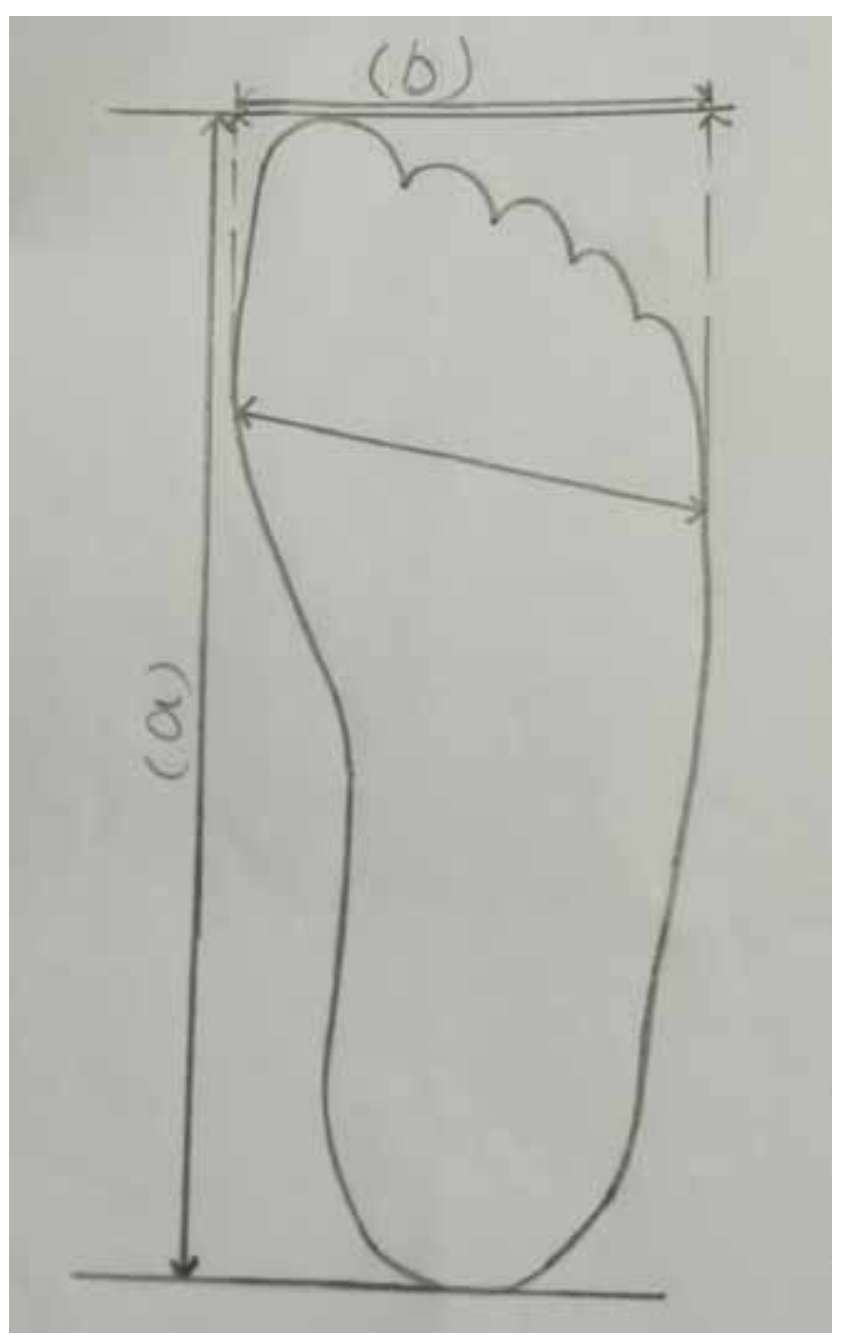

Figure 1: Measurements taken of right foot.Length (a) andWidth (b) of the foot.

Descriptive Statistics: Statistical analysis was brought about on the acquired samples. Descriptive statistics result as shown in Table 1. The measurements of the stature of individuals under study had a range between $145-177 \mathrm{cms}$. In order to yield a better correlation between the parameters and the stature, value of $p<0.001$ was considered. A significant correlation was obtained between stature estimation and Right Foot Width having the value of $\mathrm{R}=0.02$ and Left Foot Width with the value of $\mathrm{R}=0.03$. 
Table 1: Descriptive Statistics conducted for Stature estimation and Foot Measurements.

\begin{tabular}{|l|c|c|c|c|c|}
\hline Statistics & Stature & LFL & RFL & LFW & RFW \\
\hline Mean & 160.556 & 24.668 & 24.879 & 9.684 & 9.564 \\
\hline Median & 160.000 & 24.600 & 24.900 & 9.700 & 9.600 \\
\hline Mode & 159.0 & 24.1 & 24.9 & 9.5 & 9.7 \\
\hline Standard Deviation & 5.9843 & 1.0282 & 1.1108 & 0.5019 & 0.4676 \\
\hline SEM & 0.5680 & 0.0976 & 0.1054 & 0.0476 & 0.0444 \\
\hline
\end{tabular}

Table 2 determines the value obtained after conduction of simple linear regression analysis. The table shows Standard Error Estimation (SEE), the predicted correlation values $(R)$ and the percentage of variance $\left(R^{2}\right)$ thus calculated.

Table 2: Simple Linear Regression Analysis Output.

\begin{tabular}{|c|c|c|c|}
\hline & SEE & Value of $\mathbf{~}$ & Value of $\mathbf{r}^{\mathbf{2}}$ \\
\hline LFL & 5.29 & 0.46904 & 0.22 \\
\hline LFW & 5.72 & 0.3 & 0.09 \\
\hline RFL & 5.11 & 0.5196 & 0.27 \\
\hline RFW & 5.88 & 0.2 & 0.04 \\
\hline
\end{tabular}

Table 3 determines the Simple Linear Regression equations generated for the defined variables; extremely less error rate was obtained by using foot measurements of the females specifically using the width of both the left and right foot.

Table 3

\begin{tabular}{|l|c|}
\hline Parameters & Linear Regression Equations \\
\hline LFL & $\mathrm{S}=92.46+2.76(\mathrm{LFL})$ \\
\hline LFW & $\mathrm{S}=125.48+3.62(\mathrm{LFW})$ \\
\hline RFL & $\mathrm{S}=90.04+2.83(\mathrm{RFL})$ \\
\hline RFW & $\mathrm{S}=135.98+2.56(\mathrm{RFW})$ \\
\hline
\end{tabular}

ANOVA conducted on the sample yielded a significant value of 0.03 for estimating stature using RFW.

\begin{tabular}{|c|c|c|c|c|c|c|c|c|}
\hline \multicolumn{9}{|c|}{ ANOVA } \\
\hline & df & SS & MS & $\mathbf{F}$ & Significance F & & & \\
\hline Regression & 1 & 158.7317 & 158.7317 & 4.576455 & 0.034645878 & & & \\
\hline Residual & 109 & 3780.602 & 34.68442 & & & & & \\
\hline \multirow[t]{2}{*}{ Total } & 110 & 3939.334 & & & & & & \\
\hline & Coefficients & $\begin{array}{l}\text { Standard } \\
\text { Error }\end{array}$ & t Stat & P-value & Lower 95\% & $\begin{array}{l}\text { Upper } \\
95 \%\end{array}$ & $\begin{array}{l}\text { Lower } \\
95.0 \%\end{array}$ & $\begin{array}{l}\text { Upper } \\
95.0 \%\end{array}$ \\
\hline Intercept & 135.9884458 & 11.49764 & 11.82751 & $2.9 \mathrm{E}-21$ & 113.2005009 & 158.7764 & 113.2005 & 158.7764 \\
\hline RFW & 2.568747659 & 1.200762 & 2.139265 & 0.034646 & 0.188877026 & 4.948618 & 0.188877 & 4.948618 \\
\hline
\end{tabular}




\section{Discussion}

Numerous studies have been conducted in estimating the stature or height using various body measurements. A significant amount of research reveals that yielding equations using foot dimensions can be extensively used for estimating the stature of various individuals. Literary works conducted nationally as well internationally clearly mention that one single formula and equation cannot be utilized in determining the stature at universal level. Thus every population, tribe, community, locations where people have been living are key research hot spots for conducting these studies. Taneja et al ${ }^{6}$ in their study of stature estimation of the males of Udaipur, Rajasthan using foot measurements obtained a correlation coefficient between stature and dimensions of the right foot of 0.184 and 0.186 of the left foot. One more study was conducted on KORI population of Kanpur with various body measurements of both males and females. ${ }^{5}$ Thus derived regression equation for estimating the stature of the said population yields a highly significant value while determining stature using foot measurements.

Similar research using foot dimensions for estimating the stature of Gujarat Population was conducted. ${ }^{4}$ They obtained significant values of correlation coefficient between stature and foot length of both male and female. The obtained significant value for male was 0.65 and female was 0.80 . Another study wasconducted in Mahakaushal region of Madhya Pradesh. ${ }^{7}$ In their study they determined the height from foot dimension, the width and the length being the key parameters and were found to be extremely correlated with stature.

Ozaslan et $\mathrm{al}^{3}$ conducted the research on Turkish Population for estimating stature using both hand and foot dimensions. In their study they reported that length measurements yield more accurate results as compared to breadth results. Foot dimensions in male yielded a value of $\mathrm{r}=0.696$ and females reported $\mathrm{r}=0.496$. Concurringly hand dimensions in male gave a significant value of $\mathrm{r}=0.578$ contrary to females with $\mathrm{r}-0.309$ value. Moorthy $\&$ Khan ${ }^{8}$ conducted their research on Bidayuhs in east Malaysia using regression equation for estimating stature using footprints. Apart from dimensions they also incorporated gender as an indicator in stature estimating. The result showed that dimension dependent values were found to be more significant than the one that had gender as a parameter in the pooled sample population.

Giles \& Vallandigham ${ }^{9}$ used anthropometric measurements on human anatomy for determining the height on Igbo inhabitants of Imo state in Nigeria. Their findings report that foot lengths are more accurate and have high predictability rate as compared to width. Right foot showed accuracy of $50.26 \%$ in males and $44.05 \%$ in females.

Numerous scholars have predicted various measures of stature estimation that have various parameters involved after from just length and breadth dimensions. The present study conducted on females of Rajasthan population show a more significant role of width in height estimation than length. Analysis conducted on Right foot width produced a value of 0.04 which is extremely significant and on contrary Left foot width produced a significant value of 0.09 . Thus it can be concluded that the obtained regression equations can be utilized in estimating the stature from footprints of Rajasthan female population.

\section{Conclusion}

Stature estimation or height determination plays extensive role in forensic science. Its extent stretches from narrowing down the suspect list to identifying the individual. India is a large country with diverse communities thus generating a universal equation for stature estimation is not feasible. Thus research conducted on communities sharing ancestral history of location can be brought about for correct estimation of height. These collections can at a large become a database that could be used for identification purpose. Our study conducted on Rajasthan population of females achieved a significant result of equations, where both foot widths are showing highly accurate result for estimating the stature.

Conflict of Interest: FarayJamal, Rishu Agarwal, Aditi Mishra and UlhasGondhalideclare that they have no conflict of interest.

\section{Source of Funding: Self funding.}

Ethical Clearance: This study was approvedby the Institutional Ethical Committee of the Raksha Shakti University.

Acknowledgement: We want to acknowledge administration of Mody University of Science and Technology for providing us the facility for conducting of this research work Estimation of stature from foot dimensions from female population of Rajasthan 


\section{References}

1. Max M. Houck JAS. Fundamentals of Forensic Science. Second. 2010. 680 p.

2. Pearson K. Mathematical Contributions to the Theory of Evolution. V. On the reconstruction of the stature of Pprehistoric races. 1899;192:169244.

3. Ozaslan A, Karadayi B, Kolusayin MO, Kaya A, Afsin H. Predictive role of hand and foot dimensions in stature estimation. Rom J Leg Med. 2012;20(1):41-6.

4. Patel S V. Estimation of Height from Measurements of Foot Length in Gujarat Region. 2007;56(1):257.

5. Kamal R, Yadav PK. Estimation of stature from different anthropometric measurements in Kori population of North India. Egypt J Forensic Sci
[Internet]. 2016;6(4):468-77. Available from: http://dx.doi.org/10.1016/j.ejfs.2016.12.001

6. Taneja C, Babel $\mathrm{H}$, Jain LK. AN ANTHROPOMETRIC STUDY OF STATURE ESTIMATION AMONG MALES FROM THE MEASUREMENTS OF FEET IN UDAIPUR DISTRICT OF RAJASTHAN. 2016;8(17):41-5.

7. Kanwar R, Lakhanpal A V, Shrivastava S. Estimation of Height From Foot Dimensions. Int J Anat Res. 2016;4(3.3):2833-7.

8. Moorthy TN, Khan HBMA. Estimation of Stature from Footprint Anthropometry Using Regression Analysis : A Study on the Bidayuh Population of East Malaysia. Arab J Forensic Sci Forensic Med. 2015;1(1):114-22.

9. Giles E, Vallandigham PH. Height Estimation from Foot and Shoeprint Length. J Forensic Sci. 1991;36(4):13129J. 